\title{
PREDICTION OF RIVER FLOW DISCHARGE USING HYBRID NEURAL NETWORK ALGORITHM
}

\section{Imam Suprayogi}

Civil Engineering Department, Faculty of Engineering, Riau University, Pekanbaru, Indonesia

\section{Bochari}

Civil Engineering Department, Faculty of Engineering, Riau University, Pekanbaru, Indonesia

\section{Manyuk Fauzi}

Civil Engineering Department, Faculty of Engineering, Riau University, Pekanbaru, Indonesia

\section{Joleha}

Civil Engineering Department, Faculty of Engineering, Riau University, Pekanbaru, Indonesia

\section{Nurdin}

Civil Engineering Department, Faculty of Engineering, Riau University, Pekanbaru, Indonesia

\section{Muhammad Idraq Ibnuts Tsauri}

Implementing Agency and Construction Service Selection (BP2JK)

Directorate General of Housing and Innovation Works

Ministry of Public Works and Public Housing Republic of Indonesia

\section{Azmeri}

Civil Engineering Department, Faculty of Engineering, Syiah Kuala University, Banda Aceh, Indonesia

\begin{abstract}
Successful river flow forecasting is major goal and essential procedure that is necessary in water resources planning and management. In accordance with the characteristics hydrological phenomena in a river watershed area, the river flow varies irregularly. Therefore, it is difficult to predict the magnitude of discharge in the river an exactly at a certain moment. The main purpose of the research is to develop of model to predict river flow discharge to monitor the dynamics of river flow
\end{abstract}


fluctuations especially the sufficient information for Regional Water Supply Company (PDAM) Pekanbaru city continue so to operate serving the needs of drinking water for urban communities and as for the development of the flood early warning system (FEWS) in Siak river. The method of research approach used is using Self Organizing Map (SOM)- Artificial Neural Network (ANN) developed a hybrid system between algoritma SOM and ANN Backpropagation algorithm as branch of soft computing. The location of research on the of Station Automatic Water Level Record (AWLR) Pantai Cermin in Pantai Cermin Village, Kampar Residence, Riau Province. The data used in this research is secondary data of discharge sourced from River Region Agency (BWS III) Sumatera Pekanbaru, Riau province from year 2002 until 2007. The main results of the research proved the use of the model SOM-ANN better than model ANN as branch of soft computing that have advantages on recognized pattern data resulted in high prediction accuracy at river flow discharge in Siak River for one annual ahead $\left(Q_{t+1}\right)$ has a degree of very strong relationship with the value of coefficient of correlation respectively 0.9016 and 0.8589 .

Keywords: prediction, river flow, model, self organizing map, artificial neural network

Cite this Article: Imam Suprayogi, Bochari, Manyuk Fauzi, Joleha, Nurdin, Muhammad Idraq Ibnuts Tsauri and Azmeri, Prediction of River Flow Discharge Using Hybrid Neural Network Algorithm, International Journal of Civil Engineering and Technology, 11(6), 2020, pp. 89-102.

https://iaeme.com/Home/issue/IJCIET?Volume $=11 \&$ Issue $=6$

\section{INTRODUCTION}

Modeling of hydrological processes that are embedded with high complexity, dynamism, and non linearity in both spatial and temporal scales is of prime importance for hydrologist and water resources engineers. In many cases, however, the lack of physical understanding of the complex processes involved creates problems to find efficient models (Kalteh, et al., 2007).Many engineering and natural phenomenon that difficult and sophisticated, which needs to be predicted with physical model and/or mathematical model, the scientist will always involved in with modeling. In modeling, necesarily inherent inequality or error. Such error may be due to its schemes, assumptions, or because the human factors (Pratikto, 1999).

River flow forecast can be generated using type of mathematical models : rainfall runoff models and river flow models. The rainfall-runoff models use both climatic and hydrologic data, while river flow models only use hydrologic data. The river flow process in a catchment area is a complex process that can be affected by many interrelated physical factors. The factor affecting the river flow response of a catchment subjected to rainfall input include storm characteristic, such as intensity and duration of rainfall events, and so on. Moreover, the conceptual rainfall-runoff models need a large amount of data for calibration and validation purposes and are usually computational expensive and vary time consuming (Grayson, et al., 1992, Jain and Kumar, 2007; Ismail, et al., 2012). Although combining other variables may improve their prediction accuracy, but in practice, especially in developing countries like Indonesia, such information is often either not available or difficult to obtain. Moreover, the influence of these variables and many their combinations in generating river flow is an extremely complex physical process, especially due to the data collection of multiple inputs and parameters, which vary in space and time and which are not clearly understood (Zhang and Govindaraju, 2000; Jain and Kumar; Ismail, et al., 2012). Owing to the complexity of this process, many researcher are focusing on river flow forecasting, which only considers the past river flow 
data, because it offers a rapid development and minimum information requirement (Adamowski and Sun, 2010; Kisi, 2004, 2008; Wang, et al., 2009; Ismail, et al., 2012).

In Indonesia, there are five methods of river flow forecasting used by default i.e. simple forecasting method, forecasting method correlation and regression, recession forecasting method, and time series analysis method using Auto Regression (AR) method and Stochastic method Thomas-Fiering (Department of Housing and Regional Infrastructure, 2003). Conventionally, there area many forecasting techniques that have been proposed in literature for river flow forecasting. The most comprehensive of all popular and widely known statistical methods used in time series forecasting is Autoregressive Moving Average (ARMA) model, also known as the Box Jenkins model (Box, et al., 1976). Several studies have (Huang, et al., 2004; Modarres, 2007; Fernandes and Vega, 2009; Wang, et al., 2009). The weakness of such conventional methods is the quality of forecasting and the needs of many other additional parameters such as the physical nature of the catchment area and the river network (Firat and Gungor, 2007).

In the last decade, the softcomputing model as a branch of the science of artificial intelligence introduced as forecasting tool, such as artificial neural network knowlegde based system, expert system, fuzzy logic, dan genetic algorithm. The reason to select softcomputing model as tool in modeling system, is because the softcomputing works in non-linear system that is quiet difficult to model_mathematically, also have the flexibility of commonly used parameter usually constraints on other tools (Purnomo, 2004; Suprayogi, et al., 2020). One of the softcomputing components which has been applied in the hydro engineering field development is artificial neural network (ANN). Since 1990s, ANN have been basically inspired by the biological neural network consisting of a billion of interconnected neuron in the brain. With the advances in the field on information processing the massive parallel processing and distributed storage properties of the brain have simulated through artificial neural networks, ANN can be described as mathematical structure capable of representing the arbitrary, complex and non linear process correlating the input and output of any system, is gradually used in hydrological prediction, such as : rainfall forecasting (Sajikumar and Thandaveswara, 1999; Bodri and Čermák, 2000; Luk, et al., 2001); stream flow forecasting (Kim and Barros, 2001; Campolo et al., 2003; Hu et al., 2005); groundwater level prediction (Giustolisi and Simeone, 2006; Suprayogi, et al., 2020); modeling the infiltration process (Sy, 2006); reservoir operations (Hasebe and Nagayama, 2002; Chang, et al., 2005; Kim, et al., 2009 ); rainfall-runoff modelling (Wilby, et al., 2003; Giustolisi and Laucelli, 2005); parameter estimation of hydrological models (Rowinski, et al., 2005); uncertainty analysis of hydrological model parameters (Ozelkan and Duckstein, 2004); and modelling of time series (Sisman-Yilmanz, et al., 2004; Nayak et al., 2004a).

The Self Organizing Map (SOM), proposed by Kohonen (2001), is one category of ANN that was first used as information processing tool in the field of speech and image recognition. SOM has been successfully applied in clustering, classification, estimation, prediction and data mining (Vesanto and Alhoniemi, 2000; Kohonen, 2001). SOM has attracted increasing for water resources application, such as the classification of satellite imagery data and rainfall estimation (Murao, et al., 1993), rainfall-runoff modeling (Hsu, et al., 2002), typhoon rainfallforecasting (Lin and $\mathrm{Wu}, 2009$ ), river flood forecasting (Chang, et al., 2007), water resources problem (Kalteh, et al., 2007), and model evaluation (Herbst and Casper, 2008; Herbst, et al., 2009). The advantages of SOM compared with the other clustering methods have been extensively discussed in the literature (Mangiameli, et al., 1996; Lin and Chen, 2006). Mangiameli, et al., (1996) showed that SOM performed the best when compared to seven other hierarchical clustering methods. Lin and Chen (2006) recommended SOM as an alternative to the identification of homogeneous regions for regional frequency analysis where 
the results showed that the SOM determines the cluster membership more accurately than the K-means method and Ward's method. In addition, the SOM is more robust than the traditional clustering methods. Lin and Chen (2005) apply the SOM clustering for predicting the groundwater level at Hsiu Lin Station, Taiwan. Among 240 data sets, the first 192 samples are used for training and the remaining 48 samples are used fortesting. The entire data sets are than mapped in to $14 \times 14$ map sizes. The map is then devided into 15 regions or clusters to continue with the prediction model using Radial Basis Function Networks (RBFN).

\subsection{Importance River Flow Forecasting using Model SOM - ANN}

Siak River has an enormous benefits to all parties which is the domestic water source for communities along the Siak River, source of raw water (intake) for the regional water supply company (PDAM) Pekanbaru city, source of raw water for industrial, source of livelihood for fishermen along the Siak River, and means of river transportation (Sudiana, et al., 2007). Main problem based exposure the Public Work Minister at the Seminar of rescue and conservator the Siak watershed in Pekanbaru 6 August 2005 regarding spatial watershed planning at Siak Riau Province with reference to the result of research conducted by the Engineering Faculty team of Gadjah Mada University (UGM) Jogjakarta that Siak River that has a depth of 20-29 meters is the deepest river in Indonesia, but influence of the enter sediment accumulation in riverbed had reached a height of 8 meters or one third of the river depth. This indicates the existence of sizeable erosion in the upstream section. On the other hand, in rainy seasons the flood hazard may occure due to reduced of rivers storage capacity because increasing the river flow discharge.

The river flow forecasting in a hydrological process have an important role in order to produce accurate and sustainable management, planning, and utilization of the water resource. For hydrological analysis purpose, a long hydrological data required, but often found the data provided is incomplete or even none at all. In accordance with the characteristics hydrological phenomena in a river watershed area, the river flow varies irregularly. Therefore, it is difficult to predict the magnitude of discharge in the river an exactly at a certain moment. Successful river flow forecasting is major goal and essential procedur that is necessary in water resources planning and management.

\subsection{Implementation of River Flow Forecasting using Model SOM - ANN}

There are many forecasting techniques used river flow forecasting. One of the softcomputing components which has been applied in the hydro engineering field development is ANN back propagation algorithm method. The weakness of this ANN back propagation algorithm is the random determination of initial weight, so that the network training become less optimal. In an effort to overcome the weaknesses of ANN the back propagation algorithm is combining with another algorithm, such as SOM algorithm. SOM was firstly introduced by Tuevo Kohonen of the University of Helsinki in 1981. SOM is a network with unsupervised learning which is widely use, for instance to explore data mining and do clustering, which is separate input into several groups. The main advantages of the SOM algorithm are that it is non-linear and has an ability top reserve the topological structure of the data (Corne, et al.,1999;ASCE,2000).

Improving forecasting accuracy, especially in time series forecasting, is an important yet often difficult task facing decision makers in many areas. Using hybrid models has become common practice to improve forecasting accuracy. There are several studies that show that hybrid models can be an effective way to improved the accuracy of forecasting, compared to using single models separately (Zhang, 2003; Jain and Kumar, 2007). For instance, Lin and $\mathrm{Wu}$ (2009) proposed a combination of SOM and Multi Layer Perceptron (MLP) in order to 
forecast the typhoon rainfall at Tanshui River Basin. SOM was used to analyze and divide the input data into distinct clusters. The second step involved an individual relationship between the input and output data constructed by a specific MLP. For evaluating the forecasting performance of the proposed model, an application was conducted. The results show that the proposed model can forecast more precisely than the model developed by the conventional neural network approach. Srinivas, et al., (2009) combined a SOM and fuzzy clustering for regional flood frequency analysis for watersheds data from Indiana, USA. Results show that the proposed approach performs better in estimating flood quintiles at ungagged sites.

In recent years more hybrid models have been proposed, which combine a clustering technique with local forecasting models that are more accurate since these models are more specialised and have successfully solved many predictions problems, such as a combination of SOM with ANN (Pal et al., 2003; Lin and Wu, 2009; Wang and Yan, 2004), SOM with SVM (Cao, 2003; Fan and Chen, 2006; Fan,et al., 2007), SOM with RBFN (Lin and Chen, 2005), ANN with K-means (Corzo and Solomantine, 2007) and other models. Although the idea of these hybrid models is interesting and promising, it still need to be tested using a river flow time series.

Based on the same idea by Ismail, et al., (2012) this research aims to explore the application of hybrid technique and to test the capability and effectiveness of the idea of hybrid modeling which combines the SOM with the ANN (SOM-ANN). The hybrid model SOM-ANN is then proposed for river flow forecasting in order to improve the accuracy of prediction. With the advantages of the data analysis technique developed by SOM and the capability of ANN, the proposed hybrid model is expected to be useful for river flow forecasting. The results of the predictions by the SOM-ANN model are compared with a forecasting model developed by ANN models. Location of research in Automatic Water Level Record (AWLR) station Pantai Cermin, Pantai Cermin village, Tapung Sub district, Kampar District, Riau Province. The research location is presented on the Figure 1. below

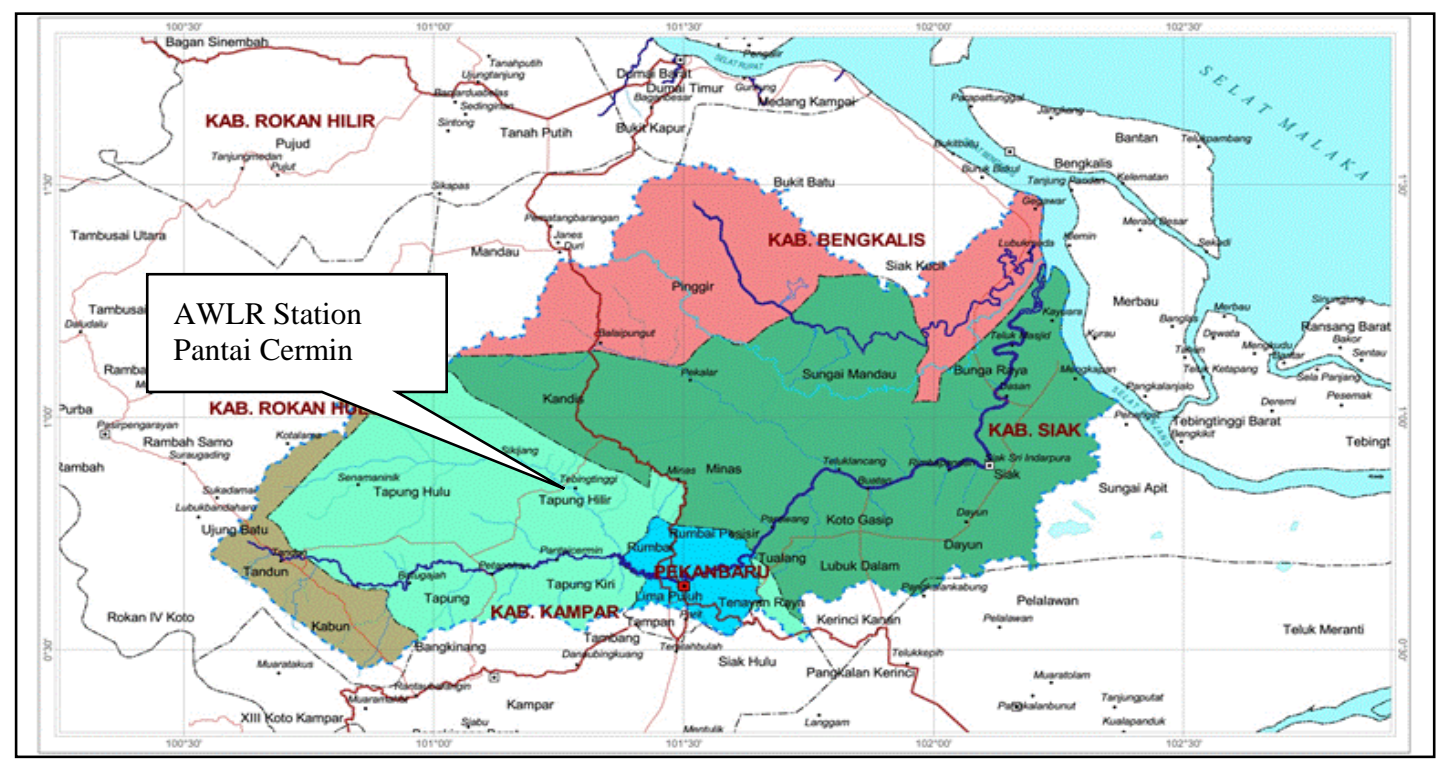

Figure 1 Location of research

Sources : River Region Agency (BWS) III Sumatera, 201 


\section{DATA USED AND PREDICTION RIVER FLOW DISCHARGE USING SOM - ANN}

\subsection{Integrating the SOM-ANN Model}

The concept of model built for the needs of river flow forecasting is a integration between SOM and ANN. SOM models have advantage in cluster process of time series data, while ANN have advantage in forecasting process that are expected able to improve model performance. Furthermore, the description of SOM and ANN combination for details is presented in Figure 2 below.

Data time series river

flow discharge at time $t\left(Q_{t}\right)$
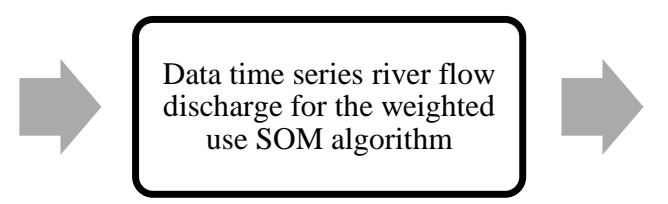

The forecasting process river flow discharge at time $\mathrm{t}+1$ $\left(\mathrm{Q}_{\mathrm{t}+1}\right)$ use ANN

Backpropagation algorithm

Figure 2 The integration of SOM-ANN model

Step solution river flow prediction model using SOM - ANN algorithm

- The preparation of data from the form Station AWLR Pantai Cermin which describe patterns of relationship between the water level as time function (stage hydrograph) from 2002-2006, which is subsequently is transformed into a discharge (discharge hydrograph) using the equation of rating curve $Q=14,78(H+0,384)^{1,580}$ that have been compiled by River Region Agency (BWS) III Sumatera in Pekanbaru.

- Clustering data discharge from year 2002-2005 is used as data to be obtained weight using SOM algorithm.

- Model development stage, $70 \%$ of total river flow discharge data year 2002-2005 is used as training data and $30 \%$ is used as test data. Then all the data of 2002-2005 is used as simulation data to see the results of the data training and testing process of the overall model development stage.

- The data of 2006 is the data that will be used for the river flow discharge prediction needs for one annual ahead using SOM - ANN rule model.

- The final process with the prediction process of inflow on reservoir after SOM-ANN model is done after a series of training process, testing and simulation of finished model. The prediction result of the SOM-ANN model (output) is then compared to the measurement result value. SOM -ANN model conformance and measurement results using statistical parameter test root mean square error (RMSE) and coefficient of correlation $(\mathrm{R})$ to get the best correlation rate result at prediction process

The performance of model SOM-ANN was studied under the statistical performance. The values of model SOM - ANN was compared with observed discharge ( $\left.Q_{\text {obs }}\right)$. The precision evaluation of the model is conducted by comparing the discharge of the model SOM- ANN simulation and the data of the available measurement results. Models can be said to be precise if there is a high correlation value between simulated and measured result data. One of the statistical parameter tests is the correlation coefficient $(\mathrm{R})$ is the value indicating the magnitude of the relation between the value of observation and the simulation value. The model precision test is done using the correlation coefficient $(\mathrm{R})$ which follows the equation as follows: 


$$
R=\frac{\sum_{i=1}^{i=N} Q_{p} Q_{m}}{\left[\sum_{i=1}^{i=N} \Delta Q_{p}{ }^{2} \sum_{i=1}^{i=N} \Delta Q_{m}{ }^{2}\right]^{1 / 2}}
$$

$$
\Delta \mathrm{Q}_{\mathrm{p}}=\mathrm{Q}_{\mathrm{pi}}-\bar{Q}_{\mathrm{p}} \text { dan } \Delta \mathrm{Q}_{\mathrm{mi}}=\mathrm{Q}_{\mathrm{mi}}-\bar{Q}_{m i}
$$

where $Q_{p}$ as the discharge observed $\left(\mathrm{m}^{3} / \mathrm{s}\right), \mathrm{Q}_{\mathrm{m}}$ is the discharge model $\left(\mathrm{m}^{3} / \mathrm{s}\right)$, and $\mathrm{n}$ is the number of samples.

Classification of the strength of degree of relationship based on result coefficient value correlation between simulation result of model and measurement result data. For $\mathrm{R}$ equals 0 has a relationship degree no correlation, $0<\mathrm{R}<0.25$ has a very weak degree of correlation relationship, $0.25<\mathrm{R}<0.50$ has a degree of insufficient correlation relationship, $0.50<\mathrm{R}<$ 0.75 has a strong correlation degree, $0.75<\mathrm{R}<0.99$ degrees correlation relationship is very strong and R equals 1 degree of perfect correlation relationship (De Farias et al, 2010; Firat, 2007)

\section{RESULTS AND DISCUSSION}

\subsection{SOM - ANN Model Development}

Classification pattern aims to obtain clusters and weights in each input group. Each pattern will be inserted into a group closest to or similar to the given input. In this research, data that will be input after the obtained weight value will be input in the Backpropagation algorithm is the discharge data from year 2002-2005. The cluster results using a SOM algorithm with a total of ten clusters can be seen in Figure 3.

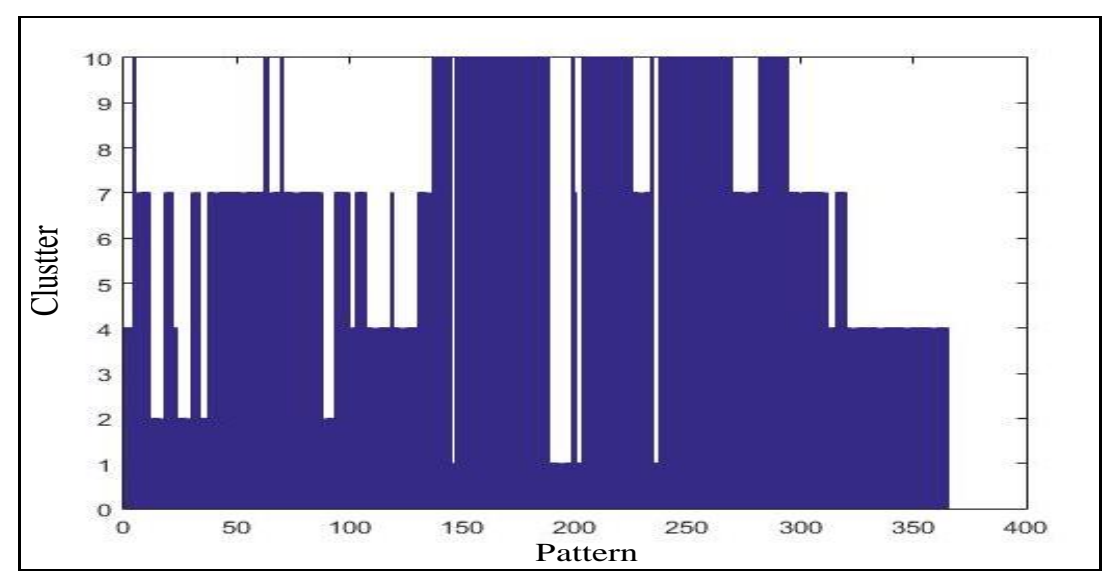

Figure 3 Result Cluster using SOM algorithm

Referring from Figure 3 above, that the distribution of the input data into ten clusters. Some clusters do not have data, such as on clusters 3, 5, 6, 8 and 9. This is because there is no data that is considered capable of representing or no match to the cluster, so there are only five clusters produced by SOM. The weight division for each cluster can be seen in the Figure 4. 


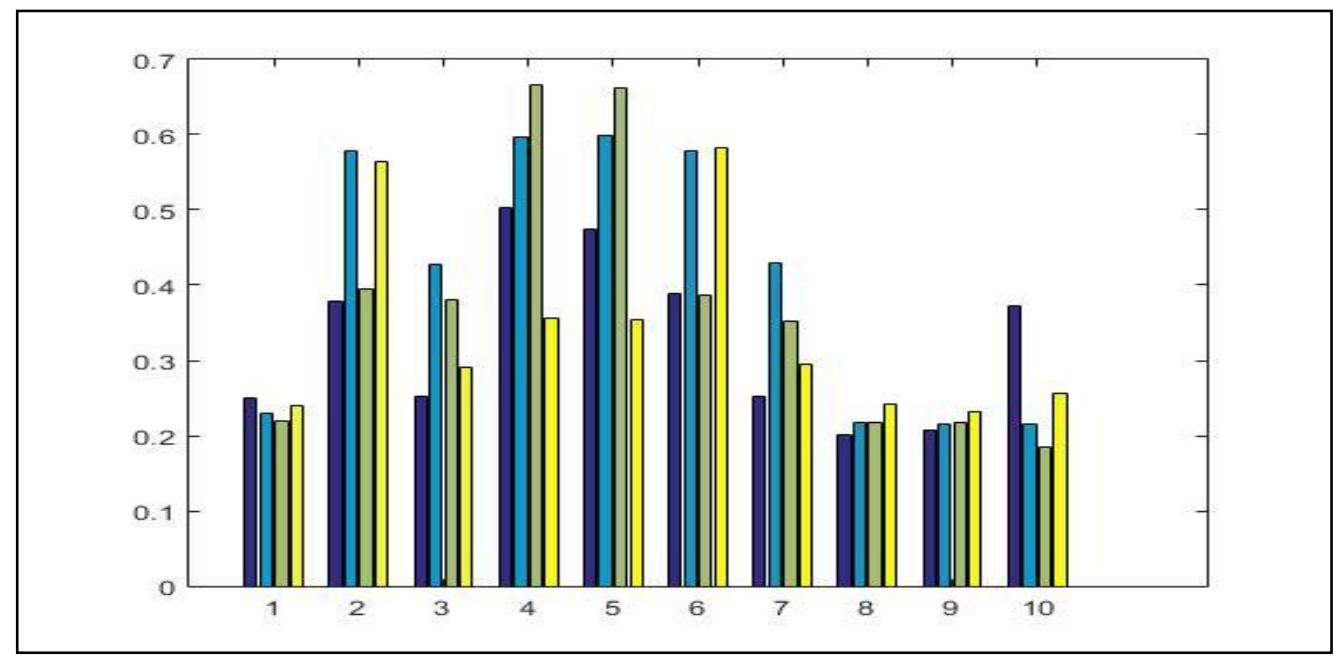

Figure 4 The weight of SOM learning results
0.594196625376094
0. 683992847694167
0.348017541115523
0.578442316866779
0.223962830328900
0.215121286480595
0.241675384809822
0.253296518544266
0. 437857627254361
0. 402245747152907
0. 304066289855801
0. 325149055214811
0. 578434473792052
0.659978687037784
0. 363909761983794
0. 575956917113870
0. 221643971106223
0. 197296182079483
0. 232238177207703
0. 271141442932942
0. 221655165032439
0. 193585522646615
0.239452120933754
0.256130283083323
0. 239470019264478
0. 198864502238232
0. 241892587557634
0. 234261330177230
0.570835200255369
0.351484964964298
0.564627001060577
0.313983256223693
0. 594029889256281
0. 379693515512605
0.583791010567860
0. 325428499354053
0.415157344017096
0. 404807332162247
0.287776804902420
0. 329145770566172

Figure 5 Weighted results of the SOM algorithm

Referring Figures 4 above, that each cluster has four different types of weights depending on the inputs on the SOM network. With four types of weights on each cluster that totaled ten clusters, the formed SOM network will have weights with the matrix order $4 \times 10$. The weight will be the initial weight of ANN training with the Backpropagation algorithm can be seen in the Figure 5.

The design of SOM algorithm - ANN with Backpropagation algorithm used the pattern of input-output taken from data of Station AWLR Pantai Cermin from 2002 until 2005. The integration SOM algorithm and ANN Backpropagation algorithm will be described Figure 6 below.

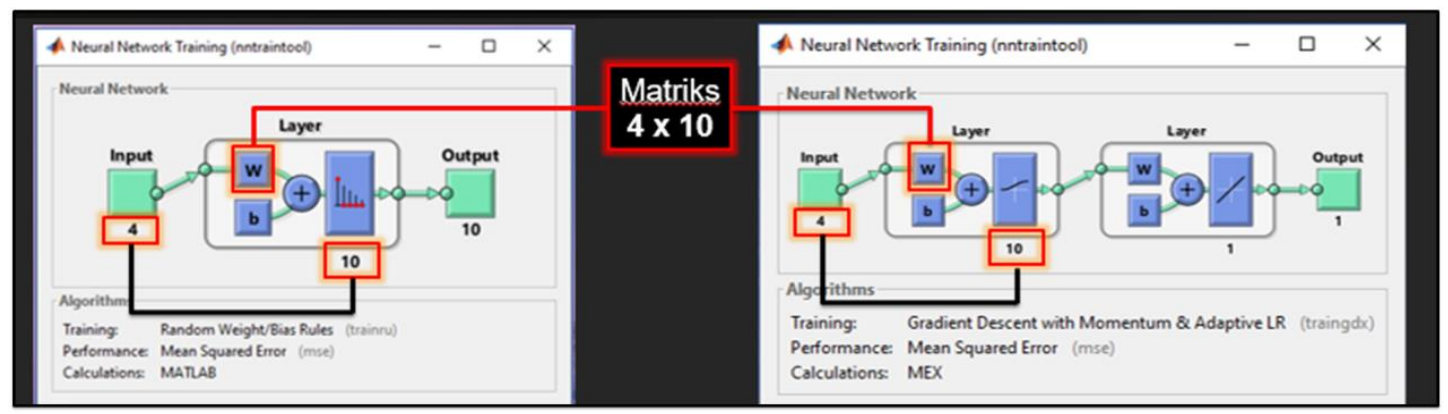

Figure 6 Integration algoritma SOM and ANN with Backpropagation algorithm as an input processes training, testing and simulation using MATLAB program 


\subsection{Training Model SOM-ANN}

The process of training model is used to train the structure of SOM- ANN. In the stage of training model using the method ANN backpropagation algorithm first done test process statistical parameters coefficient correlation ( $\mathrm{R}$ ) to get the best $\mathrm{R}$ value from the six model SOM-ANN parameters are neurons, transfer function, epochs, Max fail, learning rate, and momentum. The test result values of the next six parameters are presented as in Table 1 below

Table 1.Best parameter value of model SOM-ANN Backpropagation algorithm

\begin{tabular}{|c|c|c|c|c|c|c|c|}
\hline \multirow{2}{*}{ Parameter } & \multirow{2}{*}{ neurons } & \multicolumn{2}{|c|}{$\begin{array}{l}\text { Transfer } \\
\text { function }\end{array}$} & \multicolumn{4}{|c|}{ Parameter } \\
\hline & & layer 1 & $\begin{array}{c}\text { layer } \\
2\end{array}$ & epochs & max fail & $\begin{array}{c}\text { learning } \\
\text { rate }\end{array}$ & momentum \\
\hline & 10 & logsig & purelin & 5000 & 1000 & 0,5 & 0,9 \\
\hline
\end{tabular}

Sources : Results Running MATLAB Program

The statistical parameter test value of SOM - ANN model parameter uses the best coefficient of correlation (R), and mean square error (MSE) value on momentum and learning rate parameter of the model which is presented as shown in Table 2.

Referring Table 2 above, data training process SOM- ANN model and observation data for momentum parameters and learning rate respectively values 0.9 and 0.5 have a very strong classification with average error value approaching zeroes based on the test of statistical parameters for coefficient correlation $(\mathrm{R})$ values 0.99039 .

Table 2 Statistical test results for Momentum parameters and Learning Rate at the Data Training stage

\begin{tabular}{cccc}
\hline Statistical test & Parameter & R & Classification \\
\hline Coefficient correlation $(\mathrm{R})$ & $\mathrm{M}=0.9 ; \mathrm{Lr}=0.5$ & 0.99039 & very strong \\
\hline
\end{tabular}

Source : MATLAB program running result

\subsection{Testing Model}

After the process of training data that aims to train the structure of SOM - ANN then the next step is done the process of testing data using the architecture of SOM-ANN model consisting of three input layer and one output, which is used to assess the performance of the SOM-AN structure. Results of data testing analysis with datainput (30\% data other than the data used traning process). The full results of the data testing process using the MATLAB 7.0 program are more fully presented as Table 3 below.

Table 3 Performance of Model SOM - ANN at Phase Testing Process

\begin{tabular}{cccc}
\hline Input & Output & R & Classification \\
\hline $\mathrm{Q}_{\mathrm{t}}$, & $\mathrm{Q}_{\mathrm{t}+1}$ & 0.99039 & very strong \\
\hline
\end{tabular}

Source : MATLAB program running result

Referring from Table 3 above, it will be obtained statistical parameter test value in data testing process between SOM-ANN model and observation data in field has very strong classification with correlation coefficient $(\mathrm{R})$ values0.99039.

\subsection{Simulation Model}

The model simulation according to Refsgaard (2000) is an attempt to simulate the use of the model to obtain predicts that the water resource management can use. Model simulation stage is the last process after the training process and the testing phase. Results of the analysis of 
data simulation with data input 1 January 2002 until 31 December 2005 using the MATLAB 7.0 aids program are more fully presented as Table 4 below.

Table 4. Performance of Model SOM - ANN at Phase Simulation Process

\begin{tabular}{cccc}
\hline Input & Output & R & Classification \\
\hline $\mathrm{Q}_{\mathrm{t}}$ & $\mathrm{Q}_{\mathrm{t}+1}$ & 0.99102 & very strong \\
\hline
\end{tabular}

Source : MATLAB program running result

Referring from Table 4 above, it will be obtained statistical parameter test value in data simulation process between model SOM-ANN and observation data in field has strong classification with correlation coefficient $(\mathrm{R})$ value 0.991 .

\subsection{The Result of River Flow discharge using SOM-ANN}

The recommendation of the use of models is the final process after the training, testing and simulation of the model, which describe the performance of the river flow discharge forecasting model using SOM - ANN and ANN for one annual ahead $\left(\mathrm{Q}_{t+1}\right)$ with the result data measurements in the field, which are further presented as shown in Figure 7 and Figure 8 below.

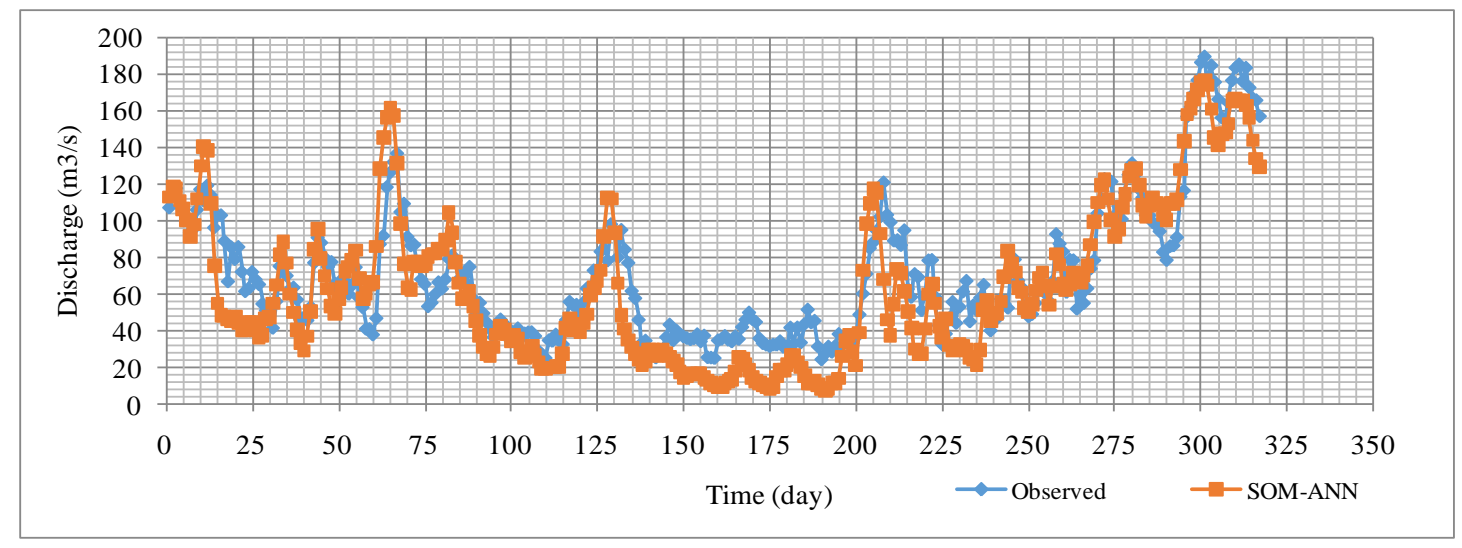

Figure 7. Description of the model SOM-ANN for river flow prediction one annual ahead $\left(\mathrm{Q}_{\mathrm{t}+1}\right)$ based on results the observation value

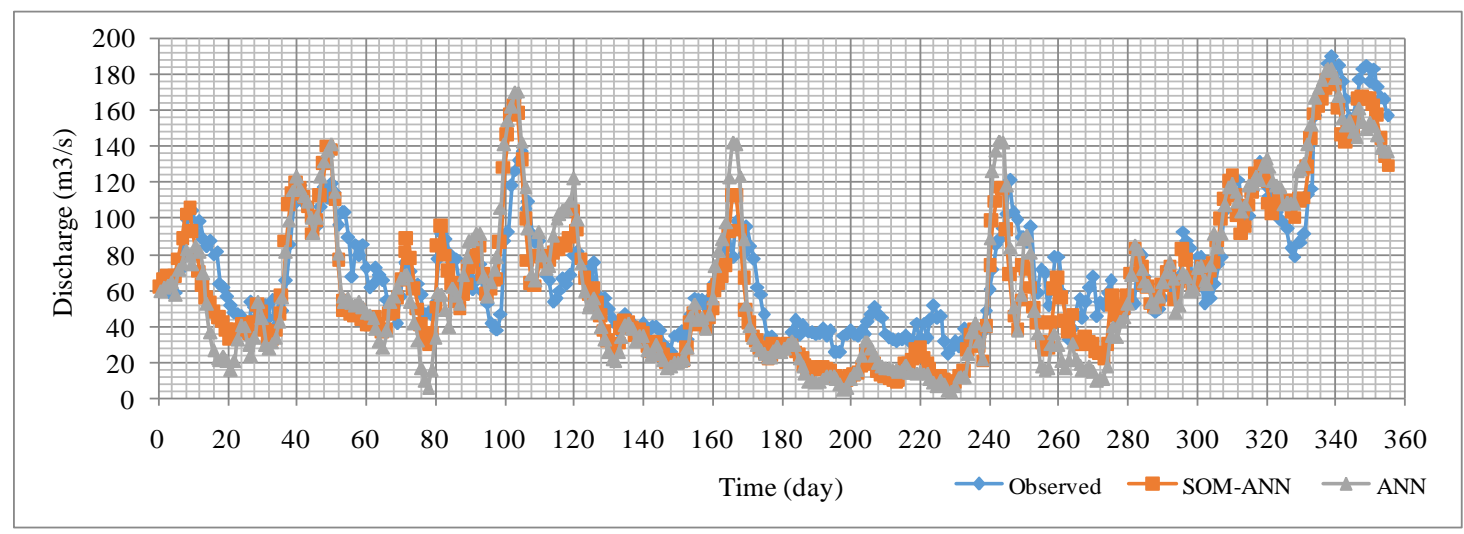

Figure 8 Description of the model SOM-ANN and ANN for river flow prediction one annual ahead $\left(\mathrm{Q}_{\mathrm{t}+1}\right)$ based on results the observation value

Source: MATLAB program running result

Referring Figure 8 above, the results of the research proved the use of the model SOMANN better than model ANN as branch of softcomputing that have advantages on recognized pattern data resulted in high prediction accuracy at river flow discharge in Siak River for one 
annual ahead $\left(\mathrm{Q}_{\mathrm{t}+1}\right)$ has a degree of very strong relationship with the value of coefficient of correlation respectively 0.9016 and 0.8589 .

\section{CONCLUSION}

Based on the analysis and discussion above, it can be recommended implementation of research results related to the development of river flow model using SOM-ANN can be used as a prediction needs to monitor the dynamics of river flow fluctuations in Siak River, especially the need for sufficient information for PDAM continue to operate serving the needs of drinking water for urban communities and as one of the inputs for the development of the flood early warning system (FEWS) in Siak river.

\section{ACKNOWLEDGEMENTS}

The author thanked the Institute of Research and Community Service (LPPM) for the support of the DIPA Riau University in 2018 through the Ministry of Research \& Technology and Higher Education, Republic of Indonesia, so River Region Agency (BWS) III Sumatera, Pekanbaru, Riau Province that has granted the use of discharge data on Station AWLR Pantai Cermin and Research Discussion Group (RDG) Softcomputing Division, Department of Civil Engineering, Riau University for the help of statistic analysis and operation of MATLAB 7.0 Toolbox program to support this research.

\section{REFERENCES}

[1] Adamowski, J., Sun, K. Development of a coupled wavelet transform and neural network method for flow forecasting of non-perennial rivers in semi-arid watersheds, Jouurnal of Hydrology, 2010, pp. 85-91.

[2] ASCE Task Committee on application of Artificial Neural Networks in Hydrology. Artificial neural networks in hydrology. I: preliminary concepts. Journal of Hydrologic Engineering 5(2), 2000, pp.115-123.

[3] Bodri, L., Čermák, V. Prediction of extreme precipitation using a neural network : Application to summer flood occurrence in Moravia, Advances 18.2012 https://doi.org/10.1016/ S0965-0.

[4] Box, G. E. P., Jenkins, G. M. Time Series Analysis Forecasting and Control. Holden Day, San Francisco, 1976.

[5] Campolo, M., Soldati, A., Andreussi, P. Artificial neural network approach to flood forecasting in the River Arno. Hydrological Sciences Journal. 48(3), 2003, pp.381-39.

[6] Cao, L. Support vector machines experts for time series forecasting, Neurocomputing 51, 2003, pp. 321-339.

[7] Chang, F. J., Chang, L. C., Wang, Y. S. Enforced Self Organizing Map neural network for river flood forecasting, Hydrological Process 21, 2007, pp. 741-749.

[8] Corne, S., Murray, T., Openshaw, S., See, L.,Turton, I. Using computational intelligence techniques to model subglacial water systems. Journal of Geographical Systems 1, 1999, pp. 37-60.

[9] Corzo, G. A, Solomantine, D. P. Base flow separation techniques for modular artificial neural network modelling in flow forecasting, Hydrological Sciiences Journal 52, 2007, pp. 491-50.

[10] De Farias, C. A. S., Alves, L. M., Santos, C. A. G., Suzuki, K. An ANN based approach to modeling sediment yield : A case study semi arid area of Brazil : Proceding of the 
ICCE Symposium Held at Warsaw Poland in Life Science -SGGW Poland, 14 - 18 June 2010 IAHS Publish 557, 2010.

[11] Department of Housing and Regional Infrastructure. River flow discharge forecasting, Research Centre and Water Resources Development, Research and Development of Agency, Department of Housing and Regional Infrastructure, Ministry of Housing and Regional Infrastructure Republic of Indonesia, 2003.

[12] Fan, S. Chen, L. Short-term load forecasting based on an adaptive hybrid method, IEEE Transactions on Power System, 21, 2006, pp. 392-401.

[13] Fernandez, C., Vega, J. A . Stream flow drought time series forecasting : a case study in a small watershed in north west Spain, Stochastic Environmental Research and Risk Assessment 23, 2009, pp. 1063-1070.

[14] Firat, M., Gungor, M. River flow estimation using adaptive neuro fuzzy inference system, Journal of Mathematic and Computer in Simulation 75, 2007, pp. 87-98.

[15] Giustolisi, O., Laucelli, D. Improving generalization of artificial neural networks in rainfall-runoff modeling. Hydrological Sciencses Journal 50 (3), 2005, pp. 439-457.

[16] Giustolisi, O., Simeone, V. Optimal design of artificial neural networks by a multiobjective strategy: groundwater level predictions. Hydrological Sciences Journal 51 (3), 2006, pp. 502-523.

[17] Grayson, R. B., Moore, I. D., Mc Mahon, T. A. Physically based hydrologic modelling. 2. Is the concept realistic, Water Resources Research 28, 1992, pp. 2659-2666.

[18] Hasebe, M., Nagayama, Y. Reservoir operation using the neural network and fuzzy systems for dam control and operation support. Advance. Engineering Software 33, 2002, pp. 245-260.

[19] Herbst, M., Casper, M. C. Towards model evaluation and identification using Self Organizing Linear Output maps, Hydrological Earth System Sciences 12, 2008, pp. 657667.

[20] Herbst, M., Gupta, H, V., Casper, M. C. Mapping model behaviours using Self Organizing Maps, Water Resources Research 13, 2009, pp. 395-409.

[21] Hu, T. S., Lam, K. C., Thomas Ng, S. A modified neural network for improving river flow prediction. Hydrological Sciences Journal. 50(2), 2005, pp. 299-318.

[22] Huang, W., Bing Xu, B., Hilton, A. Forecasting flow in Apalachicola river using neural networks, Hydrological Process, 18, 2004, pp. 2545-2564.

[23] Hsu, K., Gupta, H, V., Gao, X., Imam, B. Self organizing linear output Organizing Map (SOLO) and artificial neural network suitable for hydrological modeling and system, Water Resources Research 38, 2002, pp. 1302-1312.

[24] Ismail, S., Sabri, A., Samsudin, R. A hybrid model of self organizing maps and least square support vector machine for river flow forecasting, Hydrological Earth System Sciences 16, 2012, pp. 4417-4433.

[25] Jain, A., Kumar, A. M. Hybrid neural network models for hydrologic time series forecasting, Applied Soft Computing 7, 2007, pp. 585-592.

[26] Kalteh, A. M., Berndtsson, R. Interpolating monthly precipitation by self-organizing map (SOM) and multi layer perceptron (MLP). Hydrological Sciences Journal 52(2), 2007, pp. 305-317.

[27] Kim, T., Choi, G., Heo, J. H. Inflow forecasting for real time reservoir operation using artificial neural network : World Environmental and Water Resources Conggres : Great Rivers ASCE, 2009, pp. 4947-4955. 
[28] Kisi, O. River flow modelling using artificial neural networks, Journal of Hydrology Engineering 9, 2004, pp. 60-63.

[29] Kisi, O. River flow forecasting and estimation using different artificial neural network technique, Hydrological Researh 39(1), 2008, pp. 27-40

[30] Kohonen, T. Self Organizing Maps, New York, Springer, 501 p, 2001.

[31] Lin, G. F., Chen, L. H. Time series forecasting by combining the radial basis function network and Self Organizing Map, Hydrological Process 19, 2005, pp. 1937-1945.

[32] Lin, G. F., Chen, L. H. Identication of homogeneous region for regional frequency analysis using Self Organizing Map, Journal Hydrology 324, 2006, pp. 1-9.

[33] Lin, G. F., Wu, M. C. A. SOM based approach to estimating design hyetographs of ungauged sites, Journal of Hydrology 339, 2007, pp. 216-226.

[34] Luk, K. C., Ball, J. E., Sharma, A. An application of artificial neural networks for rainfall forecasting. Mathematic Computing Modeling 33, 2001, pp. 683-693.

[35] Murao, H., Nishikawa, I., Kitamura, S., Yamada., Xie, P. A hybrid neural network system for the rainfall estimation using satellite imagery. In : Proceedings of International Joint Conference on Neural Network IEEE Press, pp. 1211-1214, 1993.

[36] Modarres, R. Stream flow drought time series forecasting, Stochastic Environmental Research and Risk Assessment, 2007, pp. 223-233.

[37] Nayak, P. C., Sudheer, K. P., Rangan, D. M., Ramasastri, K. Fuzzy computing based rainfall-runoff model for real time flood forecasting. Hydrology Processes 17, 2004a, pp. 3749-3762.

[38] Özelkan, E. C., Duckstein, L. Fuzzy conceptual rainfall-runoff models. Journal of Hydrology 253, 2004, pp.44-68.

[39] Pal, N. R., Pal, S., Das, J., Majumdar, K. SOM-MLP: A hybrid neural network for atmospheric temperature prediction, IEEE Transactions Geoscinces Remote Sensing 41, 2003, 2783-2791.

[40] Purnomo, M. H. Soft Computing Technology : The Prospect and Its Implementation on Medical and Electric Engineering, Surabaya : Speech Inaugural to Professorship In Artificial Intelligence Science on Faculty of Electrical Engineering, Sepuluh Nopember Institute of Technology (ITS), 2004.

[41] Pratikto, W.A. Application for Modeling in Marine Engineering, Surabaya: Speech Inaugural to Professorship Field of Numerical Applications and Fluid Mechanics at Department of Marine Engineering, Faculty of Marine Engineering, Sepuluh Nopember Institute of Technology (ITS), 1999.

[42] Refsgaard, J. C. Towards a formal approach to calibration and validation of models using spatial data, in R. Grayson and G. Blöschl. Spatial Patterns in Catchment Hydrology: Observations and Modelling, Britain : Cambridge University Press, 2000, pp. 329 - 354.

[43] Rowiński, P. M., Piotrowski, A., Napiórkowski, J. J. Are artificial neural network techniques relevant for the estimation of longitudinal dispersion coefficient in rivers ? Hydrological Sciences Journal 50 (1), 2005, pp.175-187.

[44] Sajikumar, N., Thandaveswara, B. S. (1999). A non-linear rainfall-runoff model using an artificial neural network. Journal of Hydrology, 216 (1-2), 32-55. https://doi.org/10.1016/S0022-1694(98)00273-X.

[45] Srinivas, V. V.,Tripathi, S., Rao, A. R., Govindaraju, R. S. Regional flood frequency analysis by combining self organizing feature map and fuzzy clustering, Journal of Hydrology 348, 2009, pp.148-166. 
[46] Şişman Yilmaz, N. A., Alpaslan, F. N., Jain, L. ANFIS unfolded in time for multivariate time series forecasting. Neurocomputing 61, 2004, pp. 139-168.

[47] Sudiana, N., Soewandhita, H. The water resources conservation pattern of Siak watershed, Journal Alami 12 (1), 2007, pp. 1-12.

[48] Suprayogi, I., Sandhyavitri, A., Nurdin, Joleha, Wawan, Azmeri. Groundwater level forecasting model in tropical peatland using artificial neural network. International Journal of Civil Engineering and Technology. 11(2), 2020, pp.68-78.

[49] Sy, N. L. Modelling the infiltration process with a multi-layer perceptron artificial neural network. Hydrological Sciences Journal 51(1), pp. 3-20

[50] Wang, J. Yan, D. A high precision prediction method by using combination of ELMAN and SOM neural networks. In Proceeding of the first international symposiumon neural networks China, pp. 943-949, 2004.

[51] Wang, W. C., Chau, K. W., Cheng, C.T., Qiu, L. A comparison of performance of several artificial intelligence methods for forecasting monthly discharge time series, Journal of Hydrology 374, 2009, pp. 294-306.

[52] Wilby, R. L., Abrahart, R. J., Dawson, C. W. Detection of conceptual model rainfallrunoff processes inside an artificial neural network. Hydrological Sciences Journal 48 (2), 2003, pp. 163-181.

[53] Vesanto, J., Alhoniemi, E. Clustering of the self organizing map, IEEE Transcaction Neural Network 11, 2000, pp. 586-600.

[54] Zhang, B., Govindaraju, G. Prediction of watershed runoff using Bayesian concepts and modular neural network, Water Research 36, 2000, pp. 752-762.

[55] Zhang, G. P. Time series forecasting using a hybrid ARIMA and neural network model, Neurocomputing 50, 2003, pp. 159-175. 